\title{
Bio-fortification for Improving Nutritional Security
}

\author{
Ramesh Chand Bana $^{1 *}$, A. K. Gupta ${ }^{2}$, A. C. Shivran ${ }^{1}$, Ramdhan Jat ${ }^{1}$, \\ Ranjeet Singh Bochalya ${ }^{2}$ and Prabhoo Singh $^{3}$
}
${ }^{1}$ Department of Agronomy, ${ }^{3}$ Department of Soil Science and Agricultural Chemistry, SKN COA, SKN Agriculture University, Jobner-303329 (Rajasthan), India
${ }^{2}$ FSR, Sher-e-Kashmir University of Agricultural Science and Technology, Chatha, Jammu-180009 (J\&K), India

*Corresponding author

\section{Keywords}

Bio-fortification, Malnutrition,

Hidden hunger and Micronutrient

Article Info

Accepted:

24 August 2020

Available Online:

10 September 2020

\begin{abstract}
A B S T R A C T
Mostly in poorer countries especially Asia and Africa, 2 billion people suffer from micronutrient malnutrition, also known as hidden hunger (WHO and FAO 2006). This is caused by a lack of critical micronutrients such as vitamin A, zinc, and iron in the diet. Globally $\mathrm{Zn}$ is now recognized as the fifth major nutrient deficiency. Hidden hunger impairs the mental and physical development of children and adolescents and can result in lower intelligence quotient, stunting, and blindness; women and children are especially vulnerable. Hidden hunger also reduces the productivity of adult men and women due to increased risk of illness and reduced work capacity. In 2008, the Lancet published a landmark series of articles on maternal and child under nutrition highlighting the extent of hidden hunger. Hidden hunger's enormous consequences, not only to individuals but also to society through reduced economic productivity, have brought more attention to the issue recently. Also in 2008, a panel of noted economists that included five Nobel Laureates, ranked efforts to reduce-hidden hunger among the most cost-effective solutions to global challenges. One of these efforts, Bio-fortification, was ranked fifth.
\end{abstract}

\section{Introduction}

\section{Role of Agriculture to Improve Nutrition through Bio-fortification}

The agriculture is the primary source of nutrients necessary for a healthy life, but agricultural policies and technologies have focused on improving profitability at the farm and agro-industry levels, not on improving nutrition (Bouis and Welch, 2010). Given the prevalence of hidden hunger, there is growing interest in the role of agriculture should play in improving nutrition, in particular by paying more attention to the nutritional quality of food.

Bio-fortification is a scientific method for improving the nutritional value of foods already consumed by those suffering from hidden hunger (Bouis et al., 2011). Scientists first breed crops whose edible portions have 
higher amounts of nutrients. Malnourished communities receive these biofortified crops to grow and eat. When consumed regularly, biofortified foods can contribute to body stores of micronutrients throughout the life cycle. This strategy should contribute to the overall reduction of micronutrient deficiencies in a population, but it is not expected to treat micronutrient deficiencies or eliminate them in all population groups.

\section{Bio-fortification}

Bio-fortification requires experts from different fields to work together. Plant breeders explore the full spectrum of crop genetic diversity, especially seed banks, to first identify nutrient-rich germplasm, or lines, of food crops that can be used to breed more nutritious varieties. These lines are then crossed with established high-yielding lines to breed new crop varieties that not only have higher amounts of a desired nutrient, but also are high yielding and competitive with other non-biofortified varieties.

Plant breeders can use both conventional plant breeding and transgenic methods to reach their breeding targets. However, there is another approach for Bio-fortification, which is known as 'Agronomic Bio-fortification'. It will be complementary approach for Biofortification in a holistic manner (Cakmak, 2008).

\section{Agronomic Bio-fortification}

It may be defined as an approach to improve the mineral content of food crops through fertilizer applications, which are applied to the soil or directly to the leaves by foliar spray. It involves the application of zinc fertilizers to seed, soil and foliage at rates greater than those required for maximum yield to increase the uptake of nutrients into the plants and its translocation into seeds
(Bana et al., 2020a). The Harvest Zinc Fertilizer Project has found that foliar application of zinc fertilizers to wheat and rice can significantly increase zinc concentration in their grains. Depending on the extent of zinc deficiency in soils, zinc fertilizers can contribute to better yield of cereal crops. Agronomic Bio-fortification shown that $\mathrm{Zn}$ fertilization of rice and wheat also increases the $\mathrm{Zn}$ concentration in the grain and straw of rice and wheat, which can help in alleviating $\mathrm{Zn}$ malnutrition in humans and farm and dairy animals (Prasad et al., 2012). Different $\mathrm{Zn}$ fortification treatments clearly demonstrated the significant beneficial effects of $\mathrm{N}$ and $\mathrm{Zn}$ through $\mathrm{ZEU}$ was better sources of nutrient uptake by Basmati rice (grain + straw), which also improved soil quality in Basmati rice field (Bana et al., $2020 \mathrm{~b}$ ). Application of $2.0 \% \mathrm{ZnSO}_{4}$-coated urea also gave significantly higher concentrations of $\mathrm{Zn}$ in grain than separate soil application of $\mathrm{ZnSO}_{4}$ and highest $\mathrm{Zn}$ concentrations in rice grain i.e. 44 and 50.8 $\mathrm{mg} / \mathrm{kg}$ seed and straw, i.e. 88.5 and 96.1 $\mathrm{mg} / \mathrm{kg}$ straw was recorded with $2.0 \% \mathrm{ZnSO} 4-$ coated urea in 2005 and 2006, respectively (Shivay et al., 2008).

\section{Advantages of Bio-fortification}

Dietary diversity is the ultimate long-term solution to minimizing hidden hunger. This will require substantial increases in income for the poor so they are able to afford more nutritious non-staple foods such as vegetables, fruits, and animal products. Biofortification can be effective in reducing hidden hunger as part of a strategy that includes dietary diversification and other interventions such as supplementation and commercial fortification (Harvest plus, 2010).

Bio-fortification has four main advantages when applied in the context of the poor in developing countries. 
It targets the poor who eat large amounts of food staples daily

Bio-fortification is targeting the staples food crops which are major source of energy for the rural masses of the developing countries.

\section{Large stakeholders}

Bio-fortification targets rural areas where it is estimated that 75 percent of the poor live mostly as subsistence or smallholder farmers, or landless labourers. These populations rely largely on cheaper and more widely available staple foods such as rice or maize for sustenance. Despite urbanization and income growth associated with globalization, diets of the rural poor will continue to be heavily based on staple foods like cereals and tuber crops in many regions (Msangi et al., 2010). Expected increases in food prices, exacerbated by climate change, are likely to increase this reliance on staple foods.

\section{Bio-fortification is cost-effective}

After an initial investment in developing biofortified crops, those crops can be adapted to various regions at a low additional cost and are available in the food system, year after year. Ex-ante research that examined the costeffectiveness of a variety of staple crops biofortified with pro-vitamin $\mathrm{A}$, iron, and zinc in 12 countries in Africa, Asia, and Latin America found that Bio-fortification could be highly cost-effective, especially in Asia and Africa (Meenakshi, 2010). Because this strategy relies on foods people already eat habitually, it is sustainable.

\section{Availability of biofortified food on long- term basis}

Seeds, roots, and tubers can usually be saved by farmers and shared with others in their communities. Once the high-nutrition trait is bred into the crops, it is fixed, and the biofortified crops can be grown to deliver better nutrition year after year-without recurring costs.

\section{Bio-fortification: Limitations and Challenges}

Though Bio-fortification seems to be very promising tools for reduction of micronutrient deficiencies in the masses of the developing countries (Harvest Plus, 2010; Cakmak, 2008) however, these are the following major limitations and challenges with this technology:

\section{Integration of the disciplines across their boundaries}

Bio-fortification requires a paradigm shift. Agricultural science and nutrition are compartmentalized disciplines that must be integrated for Bio-fortification to succeed.

Agricultural scientists need to add nutrition objectives to their breeding programs, in addition to standard goals such as productivity and disease resistance. Plant breeders must then work closely with nutritionists to develop breeding targets for nutrients. Nutritionists and health professionals also need to accommodate agriculture-based approaches in their toolbox along with clinical interventions.

\section{Acceptance by the consumers}

Bio-fortification will be widely adopted only when proponents show that these new foods improve nutrition.

Most biofortified crops are still in the development pipeline. Nutritionists will be able to build a body of evidence that Biofortification is a viable agriculture-based intervention to improve nutrition. 


\section{Possible supply of micronutrients}

The amounts of nutrients that can be bred into these crops are generally much lower than can be provided through fortification and supplementation. However, by providing 30 50 per cent of the daily nutrient requirement, biofortified crops can significantly improve public health in countries where hidden hunger is widespread (poor consumers in many cases will already be consuming about 50 per cent of the estimated average requirements).

\section{Transgenic approaches}

These new emerging approaches can be used to improve the nutrient content of crops where natural variation in germplasm is limited. However, transgenic crops also face more regulatory hurdles compared to their conventionally bred counterparts. Whether conventionally or transgenically bred, biofortified crops should shift significant numbers of people that are receiving a little less than their estimated nutrient requirement, into a state of nutritional adequacy, for that nutrient.

\section{Target groups}

Nutritionists now focus on the 9 to 24 month age group, when micronutrients are crucial for healthy development. Infants consume relatively low amounts of staple foods and yet have relatively higher micronutrient requirements, making Bio-fortification's contribution to micronutrient adequacy in this group limited. There are exceptions; due to the particularly high vitamin A content of many orange sweet potato varieties, regular consumption of these by the mother could contribute substantially to vitamin A intakes of breastfed children 6-23 months of age. In Mozambique and Uganda, a Harvest Plus project also showed substantially improved vitamin A intakes from orange sweet potato in children aged 6-35 months (as aforementioned in the orange sweet potato success story). However, researchers need to better understand Bio-fortification's potential impact on the 9 to 24 month age group through the mother's micronutrient status going into pregnancy, when her micronutrient requirements substantially increase. This micronutrient status could be better for mothers who have consumed biofortified crops from adolescence, or even earlier.

\section{Institutionalizing Bio-fortification as a Sustainable Strategy to Address Hidden Hunger}

While substantial progress has been made to date in breeding and testing biofortified food crops, agricultural donors have been the primary investors in Bio-fortification research. Increasing the efficiency of breeding biofortified crop varieties by doing more research on the key plant genes that (i) drive translocation of minerals from soils through the plant to seeds, and (ii) are responsible for synthesis of vitamins in seeds will help in bring more agricultural decision makers on board. Moreover, research strategies that can leverage larger impacts should be supported. For example, most Bio-fortification breeding efforts are directed at increasing the levels of selected minerals and vitamins. There is promising evidence; however, that breeding for pre-biotics (non-digestible food ingredients that have health benefits) could greatly improve absorption and use of micronutrients (Bouis and Welch, 2010).

This will pave the way for scaling up Biofortification to reach millions, rather than just thousands, of households. Reaching these millions will require (a) integrating agriculture and nutritional platforms to fund and implement food-based approaches to reducing malnutrition, as was done in the 
scaling-up nutrition framework and similar initiatives; (b) creating widespread demand for more nutritious crops and foods; and (c) building institutional capacity for developing and delivering nutrient-rich crops and foods with the right mix of partners to ensure the sustainability of this strategy.

In conclusion the bio-fortification has distinct advantages that can complement other traditional approaches to improving nutrition. As more evidence emerges that nutritionally enhanced staple foods can alleviate crucial micronutrient deficiencies cost-effectively, Bio-fortification will emerge as an agriculture-based strategy that could help considerably in meeting the nutritional needs of malnourished communities throughout the world.

\section{References}

Anonymous, 2008. Copenhagen Consensus. Results, www.copenhagenconsensus.com/Home. aspx and Copenhagen Consensus, 'Micronutrient Fortification and Biofortification,' Www.copenhagenconsensus.com/Default.aspx? $\mathrm{ID}=1456$ ).

Bana, R. C., Gupta, A. K., Bazaya, B. R. and Singh, P. 2020b. Influence of ZNfertilization on nutrient uptake and soil nutrient dynamics in basmati rice $(O$. sativa L.). International Journal of Chemical Studies. 8(1):279-282.

Bana, R. C., Gupta, A. K., Puniya, R. and Singh, P. 2020a. Effect of zinc fertifortification on yield and economics of basmati rice ( $O$ sativa L.) under subtropical region of Jammu. Green Farming. 11(1):52-55.

Bouis, H. E., and R. M. Welch. 2010. Biofortification-a Sustainable Agricultural Strategy for Reducing Micronutrient Malnutrition in the Global South. Crop Science. 50 (2): S1-S13.
Bouis, H. E., C. Hotz, B. McClafferty, J. V. Meenakshi, and W. H. Pfeiffer. 2011. Bio-fortification: A New Tool to Reduce Micronutrient Malnutrition. Supplement, Food and Nutrition Bulletin. 32 (1): 31S$40 \mathrm{~S}$.

Bouis, H. E., P. Eozenou, and A. Rahman. 2011. Food Prices, Household Income, and Resource Allocation: Socioeconomic Perspectives on Their Effects on Dietary Quality and Nutritional Status, Food and Nutrition Bulletin. 32 (1): s14-s23.

Cakmak, I. 2008. Enrichment of Cereal Grains with Zinc: Agronomic or Genetic Bio-fortification?. Plant Soil. 302:1-17.

Harvest Plus, Disseminating Orange-Fleshed Sweet Potato: Findings from a HarvestPlus Project in Mozambique and Uganda. Washington, DC: HarvestPlus. 2010.

Meenakshi, J.V. , N. L. Johnson, V. M. Manyong, H. DeGroote, J. Javelosa, D. R. Yanggen, F. Naher, C. Gonzalez, J. García, and E. Meng. 2010. How CostEffective Is Bio-fortification in Combating Micronutrient Malnutrition? An Ex Ante Assessment. World Development. 38 (1): 64-75.

Msangi, S., T. B. Sulser, A. Bouis, D. Hawes, and M. Batka. 2010. Integrated Economic Modeling of Global and Regional Micronutrient Security. Harvest Plus Working Paper 5. Washington, DC: Harvest Plus.

Prasad, R., Shivay, Y.S. and Kumar, D. 2012. Bio-fortification/fertifortification of rice and wheat for ameliorating zinc malnutrition of humans and animals in India. Indian Journal of Agronomy. 57( $3^{\text {rd }}$ IAC Special Issue $): 195-198$.

Shivay, Y.S., Kumar, D., Prasad, R. and Ahlawat, I.P.S. 2008. Relative yield and zinc uptake by rice from zinc sulphate and zinc oxide coatings onto urea. Nutrient Cycling in Agroecosystems. 80(2): 181-188. 
WHO (World Health Organization) and FAO (Food and Agriculture Organization of the United Nations). 2006. Guidelines on
Food Fortification with Micronutrients. Geneva.

\section{How to cite this article:}

Ramesh Chand Bana, A. K. Gupta, A. C. Shivran, Ramdhan Jat, Ranjeet Singh Bochalya and Prabhoo Singh. 2020. Bio-fortification for Improving Nutritional Security. Int.J.Curr.Microbiol.App.Sci. 9(09): 3240-3245. doi: https://doi.org/10.20546/ijcmas.2020.909.401 